\title{
ORGANIZATION DEVELOPMENT AND PERFORMANCE: THE IMPACT OF EMPLOYEE BENEFIT PROGRAMS ON EMPLOYEE WORK BEHAVIOR
}

\begin{abstract}
Asmat Nawaz Khattak ${ }^{1 *}$
ABSTRACT

Employee Work Behaviour (EWB) is a critical aspect of organizational culture that has a substantial impact on productivity and performance. Employees are expected to behave positively at work in order to build and maintain a healthy corporate culture. Employee benefit programs are implemented by companies to increase employee commitment and performance. Employee Commitment (EC) is another important cultural attribute of a high-performing workplace. The impact of the Employee Old-Age Benefit Institute (EOBI) (Old Age Pension) on EWB was investigated, as well as the involvement of EC as a mediating factor. A quantitative research approach was used to assess the impact of EOBI (Old-Age Pension) on EWB. All EOBI-registered business units in Lahore, Pakistan, make up the population. The list of business units was provided by the EOBI office in Lahore, Pakistan. We chose a sample of 145 units from a sampling frame of five hundred using a basic random sampling approach. The study's findings demonstrate a positive and substantial relationship between EOBI (Old Age Pension) and EWB, as well as a positive and significant relationship between EC and EWB. The EC partially mediates the relationship between EOBI (Old Age Pension) and EWB. employee benefit programmes are suggested as a way to improve job performance and dedication, according to the study's findings.
\end{abstract}

Keywords: Organization Development; Employee Work Behavior; Employee Benefit Programs; Employee Commitment; Employee Old-Age Benefit Institute.

\section{INTRODUCTION}

Employee Work Behavior (EWB) and job performance are major corporate dilemmas for managers (Bashir, Amir, Jawaad \& Hasan, 2020). Organizations expect positive work behavior

\footnotetext{
${ }^{1} \mathrm{PhD}$., Superior University, Lahore, Pakistan. Email: asmat.khattak@ gmail.com

*Corresponding Author
} 
from employees to create and maintain a healthy corporate work culture. Organizational aspects like culture, job content, personal life, and the relationship of an employee with other colleagues and the work environment are the major factors that affect the work behavior of employees (Singh, 2016; Andrew, 2017; Peir'o, Bayona, Caballer, \& Di Fabio, 2020). Lutz (2011) stated that job satisfaction is a prime factor of positive work behavior. Other negative organizational cultural aspects like incivility, bullying, and aggressive behaviors are harmful to employees (Juliani \& Purba, 2019).

Positive work behaviors increase productivity, while unprofessional work behaviors lower it (Atamba, 2019). According to Haar et al. (2019), organized and responsible behavior improves an organization's image. Positive organizational controls foster professionalism and foster a performance culture. Benefits programmes and the work environment are major factors that influence job success (Chang et al., 2017). According to Wasim ul Rehman, Razzaq, and Zareen (2020), organizational atmosphere has a good and significant impact on performance, and benefits programmes promote commitment to job performance.

Employee commitment (EC) is another important cultural attribute of a high-performing workplace (Meyer, Morin, \& Wasti, 2018). Employees that are committed demonstrate selfdetermination, as well as constructive and proactive work behavior (Machokoto, 2019). EC denotes a close relationship with a company (Pham, 2017). Compensation, job satisfaction, promotional opportunities, learning and development culture, job security (Pham, 2017), job satisfaction, working climate, opportunities for training and development (Fabiene \& Kachchhap, 2016), work systems (Gul, 2015), working potentials (Radosavljevic, Cilerdzic \& Dragic, 2017), human resource practices have all been investigated as motivators and forces that accelerate EC (Brown, McHardy, McNabb \& Taylor, 2011).

A productive work environment is a significant plus (Bano \& Wajidi, 2021). Organizations use excellent social and work practices to improve productivity and bring about good change (Basheer, Muneer, Nawaz \& Ahmad, 2020). Positive and innovative work behavior is fostered by good work practices and programmes (Senol-Durak et al., 2021). To achieve a strategic employee-friendly culture, corporate managers are interested in designing and implementing employee benefit packages. More research is needed to determine the impact of employee benefit programmes on EWB. 
Employee benefit programmes are created and implemented to improve employees' economic and social security. Benefits programmes, according to Khan, Naqvi, Ghafoor, and Nayab (2020), are necessary for creative work practices and also stimulate creativity. Similarly, in recent years, the Employee Old-Age Benefit Institute (EOBI) (Old Age Pension) has gotten a lot of press. Despite the fact that pressure and interest groups have an impact on organizations (Basheer et al., 2020). Employee benefit programmes offer the best research possibilities to bridge the gap between practitioners and corporate executives. The mediating effect of EC on the association of employee benefit programmes with EWB has also been overlooked in research investigations. Corporate managers in Pakistan are concerned about employee work behavior. Employee benefit packages and employee commitment are only two examples of corporate components that influence employee behavior in the workplace (Machokoto, 2019). The impact of employee benefit programs on employee work behavior is explored in this study. Positive employee performance is accelerated by positive employee conduct. Job performance and employee behavior are linked. Employees with positive behavior will stay with organizations that can effectively develop a good culture based on mutual respect and support (Khan, Naqvi, Ghafoor, \& Nayab (2020). Employee benefit programs have a significant impact on employee work behavior.

Owing to the importance of the concepts, we have two objectives in this research project. The first is to look into the nature of the impact of EOBI (Old Age Pension) on EWB, and the second is to see if EC can mediate the interaction between EOBI and EWB. As a result, we produced the following research questions.

Research Question 1: What is the nature of the impact of EOBI (Old-Age Pension) on EWB in the organizations of Pakistan?

Research Question 2: How EC mediates the relationship between EOBI (Old-Age Pension) and EWB?

The findings of this research study are beneficial for compensation and benefits managers in understanding the significance of the EOBI-Old-Age Pension scheme. This study will assist them in identifying that organizations need to design more benefits programmes like EOBI (Old-Age Pension) to improve commitment and job performance. A critical review of existing literature is conducted, and hypotheses for the study are developed. The literature review is followed by the research methodology, used. Research methodology is followed by the analysis, results, and conclusions. Lastly, the limitations of the study and directions for future research are discussed. 


\section{LITERATURE REVIEW}

\section{The Employee Old-Age Benefits Institution}

EOBI was formed in 1976 under the Employees' Old-Age Benefits Act (1976), in accordance with Article 38-C of the Islamic Republic of Pakistan's Constitution. The Employees' Old-Age Benefits Act of 1976 was signed into law on April 8, 1976, was published on April 19, 1976, and went into effect on July 1, 1976. "The State shall provide for all persons engaged in the service of Pakistan or otherwise, social security by obligatory social insurance or other measures," says Article 38-C of the Constitution of the Islamic Republic of Pakistan.

"As soon as practicable following the beginning of this Act, the Federal Government shall create or nominate by notification an Institution to be known as Employees' Old-Age Benefits Institution," according to clause 2.4 of the EOB Act (1976). Employees of the State, Statutory Bodies, Police, Armed Forces, Railway, Local Bodies, and Municipal Committees are all immune from the application of the EOB Act (1976). Employees now make a contribution of $1 \%$ of the minimum wage, which is currently Rupees 80 per month, beginning in July 2001.

The EOBI Act covers a wide range of benefits (1976). The survivor of a deceased pensioner is entitled to a Survivor's Pension. If an insured person dies while working in an insurable job and has at least 3 years of insurable experience on his record, if an insured individual dies while not in insurable employment but has at least 5 years of insurable employment, the surviving spouse is entitled to a minimum pension of Rupees 3600 per month. An old-age grant is given to an insured person who is otherwise ineligible for an old-age pension and has reached the age of 60 in the case of males and 55 in the case of women.

The present government boosted the old-age pension from Rs. 6,500 to Rs. 8,500. Social security programmes aid low-income families financially and morally. The state prioritizes social and economic security. Old Age Pension, Invalidity Pension, Survivors Pension, and Old Age Grants are some of the monetary benefits provided by the EOBI (Pakistan Economic Survey 2018-19). Table 1 shows the efficiency and distribution benefits of EOBI.

Table1. The Details of Disbursed Benefits July 2018 - March 2019.

\begin{tabular}{clcc}
\hline S. No. & \multicolumn{1}{c}{ Benefits } & Number of beneficiaries & $\begin{array}{c}\text { Amount of benefits to be paid } \\
\text { Rupees millions }\end{array}$ \\
\hline $\mathbf{1}$ & Old-Age Pension & $2,45,870$ & $14,241.98$ \\
\hline $\mathbf{2}$ & Invalidity Pension & 5,486 & 307.02 \\
\hline $\mathbf{3}$ & Survivors' Pension & $1,46,050$ & $8,484.52$ \\
\hline $\mathbf{4}$ & Old-Age Grant & 4534 & 262.75 \\
\hline & Total & $\mathbf{4 , 0 1 , 9 4 0}$ & $\mathbf{2 3 , 2 9 6 . 2 7}$ \\
\hline
\end{tabular}

Source: Pakistan Economic Survey (2018-19): Government of Pakistan 
Employer-sponsored benefits have been examined by Dulebohn, Molloy, Pichler, and Murray (2008), who believe that future research studies should examine employer-sponsored and government-sponsored benefits and their correlations with employee behavior. Employee benefit decisions are critical for management in order to recruit and retain top workers (Judge \& Larsen, 2001; Matsuo, 2019). They claimed that employee benefits research projects receive insufficient attention. The objective of this study is to fill this void by highlighting the impact of a governmentsponsored pension programme on employee work behavior in Pakistan's private sector. We recognize that improving employee commitment by providing economic stability and welfare through employer-sponsored and government-sponsored benefits programmes. Employees who are loyal and dedicated to their jobs exhibit great work behavior (Basheer et al., 2020; Bano \& Wajidi, 2021).

\section{Employee Work Behavior}

Employee work behavior (helpful behaviors, job in-role and extra-role performance, and innovation) is a response to a specific workplace scenario (Nilsen \& Ringholm, 2019; Kiazad et al., 2019). Employee conduct is a critical component of company culture that has a significant impact on employee performance (Kiazad et al., 2019). Employees exhibit behaviors such as job satisfaction, commitment, self-directed learning, dedication, loyalty, teamwork, team-oriented conduct, absenteeism, and resignation in response to corporate initiatives (Andrew, 2017; Lutz, 2011). Employee work behavior, contentment, and performance have piqued researchers' interest (Lutz, 2011). Many studies have looked into the use of EWB in the workplace. Kumari and Pandey (2011) have concluded that are various factors of disinterest at work. They include personal reasons, attitude of co-workers and the work itself. Productive work environment yields creativity and efficiency. Boredom cause extreme lack of interest.

Singh (2016) investigated the factors that influence how people behave at work. They claimed that a person's behaviour is influenced by both his or her personality and the environment in which he or she works. Personality, perspectives, talents, and abilities influenced employee behaviour (Mustaf \& Ali, 20219). Many other research studies have attempted to determine what produces EWB that is positive. Kurose (2013), for example, said that motivation is crucial in shaping behaviour and that further research on motivation and behaviour is required. 
Abou Elnaga (2012) has advocated that individual perception and demographics shape productive, nonproductive, and counterproductive work behavior. They defined that "Perception is a process that involves selection, organization, and interpretation of environmental factors, from shapes to people and other stimuli. Through the perceptual process individuals attempt to make sense of the stimuli they receive". Loku and Gogiqi (2016) have declared that behavior is the combination of individual and environmental characteristics. Comfortable workplace and same rules and regulations for everyone encouraged employees (Lestari \& Rizkiyah, 2021). Dissatisfaction is caused by complex reporting structures. One of the most important factors is job satisfaction. Workers must feel important in order to develop a positive attitude as well as a sense of loyalty and attachment (Gudep 2019).

Negative behaviors such as incivility, aggression, and lower frequency damaging organizations. According to Sprigg, Martin, Niven, and Armitage (2010), undesirable behavior like violence, bullying and incivility cause anxiety, depression, emotional exhaustion, post-traumatic symptoms, general mental strain, and physical health symptoms. Personality qualities, low levels of selfcontrol, the use of irregular rewards, and a performance evaluation system focused on outcomes are all key predictors of counterproductive job behaviour. Employees that engage in counterproductive work behavior can harm their company by speaking ill all of the time. Employees that engage in unproductive work behavior are more likely to embezzle funds and falsify records (Senol-Durak, Durak, \& Gencoz, 2021).

Here is a question. What is the definition of work behavior? Many models are offered in the literature to elucidate miracles and conceptualize work behavior (Kovacevic, Cizmic \& Mihailovic, 2014). The method of conducting work that leads to a specific result. Work behavior should not be judged solely on the basis of its outcomes. Performance, organizational citizenship, and creativity are all aspects of work behavior (Bano \& Wajidi, 2021). Work behavior is linked with the task considering human relations, but it also causes absenteeism, unhelpful and threat behavior. Work behavior is based on human traits such as experience, ability, job security, and environmental influences (Silva, Hakim, Zanetta, Pinheiro, Gemma, \& da Cunha, 2021). Workplace conduct is heavily influenced by discipline.

Research studies have clarified that there are two types of work behavior. The first type is connected with tasks, job role and responsibilities and the second is the contextual. Contextual behavior is the approach of organizational effectiveness the impact on organizational resources. 
Kovacevic, Cizmic and Mihailovic (2014) have integrated the features of work behavior and stated that personal aspects attitude toward organization, motivation and inclination to counterproductive behavior, organizational citizenship like behaviors, efficiency and efficacy are the components of work behavior.

\section{Employee Commitment (EC)}

EC is a hallmark of a positive business culture (Machokoto, 2019). EC is a sense of belonging to a job function and an organization (Pham, 2017; Okemwa, Atambo, Muturi. 2019). Compensation systems, job satisfaction, learning and development culture, job security (Pham, 2017), job satisfaction, working climate, opportunities for training and development (Carmeli \& Freund, 2004; Fabiene \& Kachchhap, 2016), work systems (Gul, 2015), working potentials (Radosavljevicet al., 2017), and human resource practices are all shown to accelerate EC in the literature. For testing, we devised the following hypothesis.

H1: The relationship between old-age pension scheme and EWB is positive and significant.

H2: The relationship between EC and EWB is positive and significant.

H3: Enhancing EC mediates the positive relationship between old-age pension scheme and EWB.

\section{CONCEPTUAL FRAMEWORK}

The following conceptual framework was developed for this study. In the framework, EOBI (OldAge Pension) is a dependent variable, EWB is a dependent variable and EC is a mediating variable.

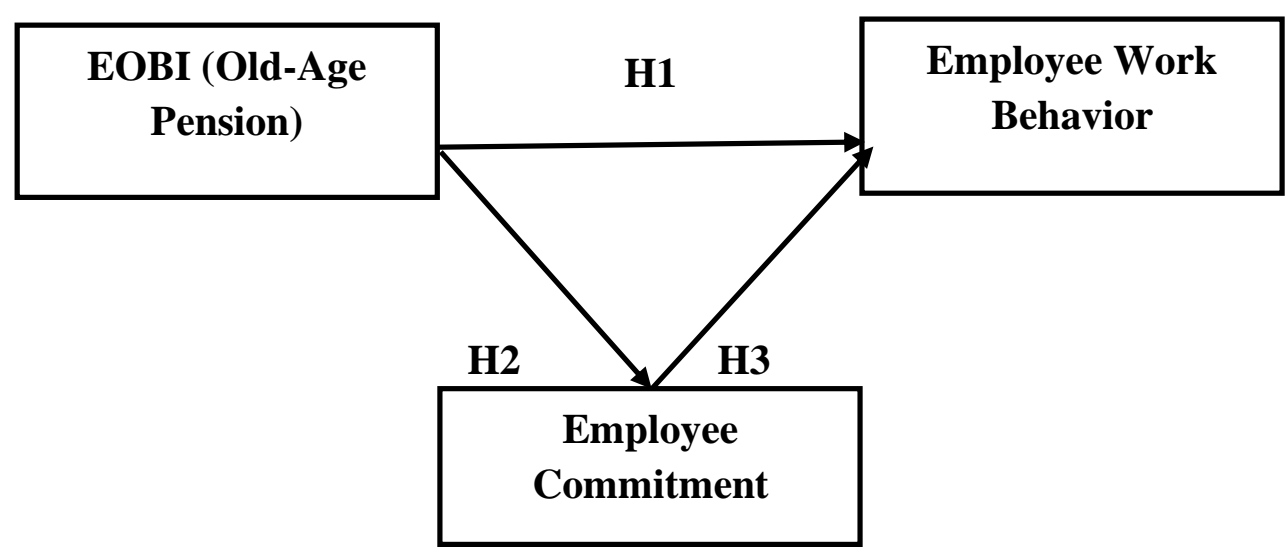

Figure 1. Conceptual Framework of the Research 


\section{METHODOLOGY}

The impact of EOBI (Old-Age Pension) on EWB was investigated using a quantitative research approach. The EC's role is that of a mediator. The population consists of all EOBI-registered business units in Lahore, Pakistan. The EOBI office in Lahore, Pakistan, provided the list of business units. We utilized a simple random sampling strategy to select a sample of 145 units from a sampling frame of 500 units. The fact that it is the most reliable probability sampling technique and lowers selection bias and random sampling error is a big advantage (Pathak, 1988). To acquire study data, we emailed a closed-ended questionnaire to each unit's Human Resource Head. Participants' responses were collected using a five-point Likert-type Scale (1=strongly disagree to $5=$ strongly agree).

For data processing and analysis, we used IBM Statistical Package for the Social Sciences (IBM SPSS Statistics). The impact of EOBI (Old-Age Pension) on EWB was investigated using regression models. Regression coefficients are used to measure the strength of hypothesized causal relationships. The standardized regression coefficient (beta) is calculated to evaluate the strength and direction of the relationship between variables for statistical significance and to ensure that the mediation analysis conditions are met, as stated by Baron and Kenny (1986).

We also calculated the t-statistic and p-values, as well as the adjusted R2 and F-statistics. To analyze the impact of the mediator on the connection of the independent and dependent variables, we used Baron and Kenny's (1986) four-step technique. Goodman and Sobel to confirm the mediations between factors, tests were undertaken using Preacher and Leonardelli's web-based technique (2001).

\section{ANALYSIS AND RESULTS}

This section discusses the analysis and results. The demographic profile of participants, reliability of measures, regression analysis, mediation analysis

\section{Demographic Profile of the Participants}

We distributed 150 questionnaires to Human Resource Heads of industrial organizations in Lahore, Pakistan, and obtained 145 responses. Table 2 shows the demographic characteristics of the participants. 
Table 2. Demographic Profile of Participants

\begin{tabular}{lcc}
\hline Demographics & Frequency & Percentage \% \\
\hline Gender (N=145) & 130 & $89.65 \%$ \\
Male & 15 & $10.34 \%$ \\
Female & & \\
Age (N=145) & 25 & $17.24 \%$ \\
Below 25 & 70 & $48.27 \%$ \\
$26-35$ & 30 & $20.68 \%$ \\
36-45 & 20 & $13.79 \%$ \\
46-55 & & \\
Qualification (N=145) & 130 & $89.5 \%$ \\
MBA & 10 & $06.89 \%$ \\
MS/MPhil & 5 & $03.44 \%$ \\
PhD & & \\
Type of Industry (N=145) & 20 & $13.79 \%$ \\
Chemicals & 50 & $34.48 \%$ \\
Pharmaceuticals & 50 & $34.48 \%$ \\
Textile & 07 & $04.82 \%$ \\
Education & 05 & $03.44 \%$ \\
Beverages & 05 & $03.44 \%$ \\
Hotel & 05 & $03.44 \%$ \\
Construction & 03 & $02.06 \%$ \\
Health Services & & \\
Total Experience in the Profession (N=145) & 100 & $68.96 \%$ \\
1-10 & 30 & $20.68 \%$ \\
11-20 & 15 & $10.34 \%$ \\
Above 20 & & \\
Experience in the Organization (N=145) & 120 & $82.75 \%$ \\
1-10 & 20 & $13.79 \%$ \\
11-20 & 05 & $03.44 \%$ \\
Above 20 & & \\
Legend: PhD: Doctor of Philosophy, MS.: Master of Science, M. Phil. Master of \\
Philosophy, MBA: Master of Business Administration & \\
& &
\end{tabular}

\section{Reliability of the Measurement Tool}

The internal consistency and reliability of each construct's components were determined. The Cronbach's alpha values are shown in Table 3. The values have a high level of internal consistency and reliability. EOBI (Old Age Pension) (alpha=0.87), EWB (alpha=0.98) and EC (alpha=0.97).

Table 3. Reliability of the Measurement Tool

\begin{tabular}{llll}
\hline Constructs & Valid N & Number of Items & Cronbach's alpha \\
\hline EOBI (Old Age Pension) & 145 & 4 & 0.87 \\
\hline EWB & 145 & 3 & 0.98 \\
\hline EC & 145 & 4 & 0.97
\end{tabular}

Note: This table reports values of Cronbach's alpha of variables

\section{Regression Analysis}

A regression analysis is carried out. The purpose of regression analysis is to determine the degree and direction of a relationship between the two variables. 
Table 4. Regression Analysis

\begin{tabular}{ccc}
\hline Independent Variable & \multicolumn{2}{c}{ Dependent Variables } \\
\hline & EWB & EC \\
\hline EOBI (Old Age Pension) & $0.444 *(15.292)$ & $0.532 *(16.232)$ \\
\hline Adjusted R & 0.187 & 0.199 \\
\hline F-Statistic & $170.165^{*}$ & $150.143 *$ \\
\hline
\end{tabular}

Note: Values in parenthesis represent t-ratios, and $\beta^{*}$ denotes significance at less than 0.05 .

Table 5. Regression Analysis

\begin{tabular}{cc}
\hline Mediating Variable & \multicolumn{1}{c}{ Dependent Variable (EWB) } \\
\hline EC & $0.555^{*}(21.222)$ \\
\hline Adjusted $\mathrm{R}^{2}$ & 0.336 \\
\hline F-statistic & $380.222^{*}$ \\
\hline Note: $\beta$ * indicates a level of significance of less than 0.05. \\
T-ratios are represented by the value in parentheses.
\end{tabular}

Results in Table 4 show that EOBI positively and significantly affects employees EWB ( $\beta=0.444$, sig. <0.01). The value of $\mathrm{R}^{2}(0.187)$ represents that $18.7 \%$ variation in EWB is explained by the independent variable. The F-statistic (170.165) is significant at less than $1 \%$ significant level which shows that the model is a good fit. Results in Table 4also show that the impact of EOBI on EC is positive and significant $(\beta=0.532$, sig. $<0.01)$. The value of $\mathrm{R}^{2}(0.199)$ represents that $19.9 \%$ variation in EC is explained by the independent variable. The F-statistic (150.143) is significant at less than $1 \%$ significant level which reveals that the model is a good fit.

Analysis further shows (see Table 5) that the impact of dependent variable (EC) on dependent variable (EWB) is positive and significant. The F-statistic is significant at less than $1 \%$ which postulates that the effect of variable is significant (see Figure 2).

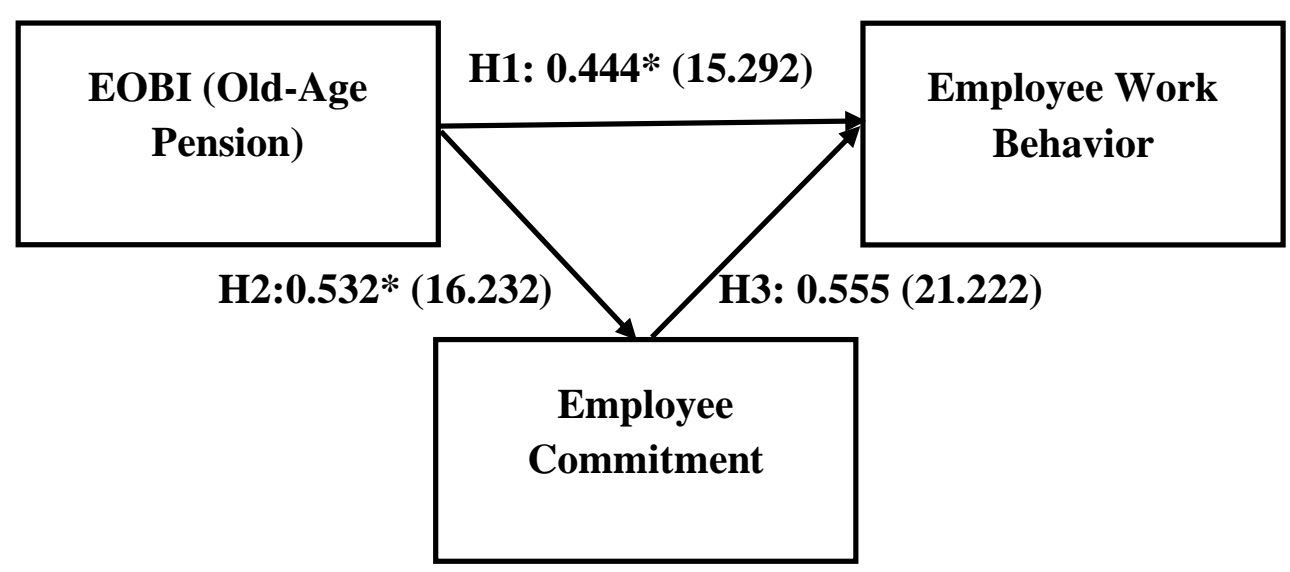

Figure 2. Results of Regression Analysis and Mediation Analysis Note: $\beta^{*}$ Represents significance at less than 0.01 and values of $t$ statistic 


\section{Mediation Analysis}

The direct effect of the independent variable on the dependent variable was examined in order to confirm Baron and Kenny's mediation conditions (1986). Table 6 shows the results of the mediation analysis. EOBI has a positive and considerable direct effect on EWB (see Table 4). The mediation study shows that EC partially mediates the association between EOBI and WEB (see Table 6).

Table 6. Mediation Analysis

\begin{tabular}{cc}
\hline Independent Variable & Dependent Variable (EWB) \\
\hline EOBI (Old Age Pension) & $\begin{array}{c}0.306^{*} \\
(8.22)\end{array}$ \\
\hline EC & $0.655^{*}$ \\
& $(18.23)$ \\
\hline Adjusted R & 0.580 \\
\hline F-statistic & $450.0^{*}$ \\
\hline Note: The value in parenthesis reflects & t-rations, and the $\beta^{*}$ \\
represents significance at less than 0.01.
\end{tabular}

\section{Sobel and Goodman Tests}

Sobel and Goodman tests are conducted to confirm the mediation among variables which assume the null hypothesis of no mediation. We used the web-based method given by Preacher and Leonardelli (2001). The result of Sobel and Goodman tests are presented in Table 7.

Table 7. Sobel and Goodman Tests

\begin{tabular}{|c|c|c|c|c|c|c|c|c|}
\hline IV & $\begin{array}{c}\text { Mediating } \\
\text { Variable }\end{array}$ & $\begin{array}{c}\text { Dependent } \\
\text { Variable }\end{array}$ & $\begin{array}{c}\text { Sobel Test } \\
\text { Statistic }\end{array}$ & $\begin{array}{l}\text { Std. } \\
\text { error }\end{array}$ & p-value & $\begin{array}{c}\text { Goodman Test } \\
\text { Statistic }\end{array}$ & $\begin{array}{l}\text { Std. } \\
\text { error }\end{array}$ & $\mathrm{p}$-value \\
\hline EOBI (Old Age Pension) & E.C & EWB & 5.410 & 0.010 & 0.000 & 3.570 & 0.044 & 0.000 \\
\hline
\end{tabular}

Note: This table presents the results of Sobel and Goodman tests

The results of Sobel and Goodman tests presented in Table 7 show the mediation between variables. We reject null hypothesis of no mediation. Results of regression analysis (see Table 4 and Table 5), mediation analysis (see Table 6) and Sobel and Goodman test (see Table 7) confirm the positive and significant relationships between EOBI (Old Age Pension) and EWB and EC and EWB. Analysis further established that EC mediates the positive relationship between EOBI (Old Age Pension) and EWB. We rejected null hypothesis in all cases and the following alternate hypothesis $\mathrm{H} 1, \mathrm{H} 2$ and $\mathrm{H} 3$ are accepted.

H1: The relationship between EOBI (Old Age Pension) and EWB is positive and significant.

H2: The relationship between EC and EWB is positive and significant.

H3: Enhancing EC mediates the positive relationship between EOBI (Old Age Pension) and EWB. 


\section{CONCLUSIONS}

We had two goals in mind. The first was to look at the impact of EOBI (Old Age Pension) on EWB, and the second was to see if EC could mediate the relationship between EOBI (Old Age Pension) and EWB. Both of our objectives were met. The relationship between the EOBI (Old Age Pension) and the EWB are positive and significant, as is the relationship between the EC and the EWB.

Another significant cultural element of a high-performing workplace is employee commitment. Committed employees exhibit self-determination as well as positive and proactive job behaviour. A close relationship with a firm is denoted by the EC. Economic security and workers' programs improve employee commitment. Loyal and committed employees show positive work behavior. Job performance is a main aspect of employee work behavior. Job performance is to fulfill the contents of job description. Job satisfaction is a prime force that effect job performance. Research studies have stated that happy employees are more productive (Dulebohn et al., 2009). Ahmed and Hassan (2020) have investigated that best human resource programs and practices improve performance. Moreover, we established that EC partially mediates the positive relationship between EOBI (Old- Age Pension) and EWB.

Employee behaviour is strongly linked to both employer-sponsored and government-sponsored perks. In order to recruit and retain top talent, management must make important decisions about employee perks. We found that the government-sponsored pension programme has a significant favorable impact on employee work behaviour in Pakistan's private sector. We understand that giving economic security and well-being to employees through employer-sponsored and government-sponsored benefit programmes strengthens employee commitment. Employees who are dedicated and faithful to their jobs have outstanding work habits (Bano \& Wajidi, 2021).

\section{THEORETICAL AND PRACTICAL IMPLICATIONS}

In terms of employee work behaviour (EWB) and job performance, managers face significant obstacles. This study looked at the effects of EOBI (Old-Age Pension) on employee work behaviour, as well as the mediation effect of employee commitment on the connection. Employee benefit plans, according to the study, improve job performance and commitment. EC is a calming effect that helps people stay on track. Employees that are committed to their jobs display positive behaviour. According to the findings, EOBI (Old-Age Pension) has a positive effect on work behaviour. Employee work behaviour (EWB) is a crucial aspect of Pakistani corporate culture that 
has a significant impact on productivity and performance. To establish and sustain a strong company culture, employees are required to act favorably at work.

Employee benefit packages are important antecedents to employee commitment and job performance, according to the research (Ahmed \& Hassan, 2020). The significance of the EOBI Old-Age Pension Scheme is crucial in the development of positive workplace practices. The current study adds to the literature by looking into the function of employee benefit packages in influencing job performance. According to Khan, Naqvi, Ghafoor, and Nayab (2020), benefits programmes are crucial for creative work practices and help inspire creativity in Pakistani businesses. The programmes are now being implemented ineffectively.

This research study has made significant contributions to the field of practice. Employee benefit programs and practices are implemented to address workplace behavioral concerns (Bhatti \& Qureshi, 2007). Employee benefit programs improve work behavior (Bano \& Wajidi, 2021; Federal benefits in Pakistan, including retirement plans, are superior strategies, and these plans should be expanded to other sectors. The findings of this research give direction to corporate planners to take employee benefit programs to a strategic level. In Pakistan, EOBI (Old Age Pension) is applicable in the private sector. Research studies suggest that the EOBI (Old-Age Pension) strategy must be incorporated into the overall business strategy (Ahmad \& Shaheen, 2011). According to the findings, the EOBI Old-Age Pension Scheme is the most powerful motivator of behavioral change.

\section{LIMITATIONS AND FUTURE RESEARCH DIRECTIONS}

We used quantitative research methods to examine the impact of EOBI (Old Age Pension) on employee work behavior. Mixed methods and qualitative methods may be used to investigate and explore the association between benefits programs and employee work behavior. The relationship between EOBI (Old Age Pension) and EWB is an outstanding business phenomenon. Other aspects of benefit programs need further exploration. The current study used the job performance dimension of employee work behavior. Future research studies may examine other aspects of employee work behavior. We used employee commitment as a mediator. We recommend that future research studies use other constructs as mediators. 


\section{REFERENCES}

Abou Elnaga, A. (2012). The impact of perception on work behavior. Kuwait Chapter of Arabian Journal of Business and Management Review, 2(2), 56 - 71.

Atamba, C. (2019). Restorative effects of awe on negative affect after receiving negative performance feedback. Journal of Psychology in Africa, 29(2), 95-103.

Addo, S. K. (2020). Analyzing the Factors that Influence Employee Satisfaction. Finance \&Management Engineering Journal of Africa, 2(5), 1 - 8.

Ahmed, K. A., \& Hassan, M. (2020). Contemporary HR practices in developing countries empirical evidence from Pakistan. City University Research Journal, 10(2), 300 -320.

Ahmad, Z., \& Shaheen, W. A. (2011). Impact of employee commitment on organizational performance, Arabian Journal of Business and Management Review, 1, 87-98.

Andrew, A. (2017). Employees' commitment and its impact on organizational performance. Asian Journal of Economics, Business and Accounting, 5(2): 1 - 13.

Baron, R. M., \& Kenny, D. A. (1986). The moderator-mediator variable distinction in social psychological research: Conceptual, strategic, and statistical considerations. Journal of Personality and Social Psychology, 51(6), 1173 - 1182.

Basheer, M. F., Muneer, S., Nawaz, M. A., \& Ahmad, Z.(2020). The Antecedents of Corporate Social and Environmental Responsibility Discourse in Pakistan: Multiple Theoretical Perspectives. Abasyn Journal of Social Sciences, 13(1), 1 - 11.

Bashir, A; Amir, A; Jawaad, M., \& Hasan, T. (2020). Work conditions and job performance: An indirect conditional effect of motivation, Cogent Business \& Management, 7(1), 1 - 16.

Bhatti, K.K. \& Qureshi, T.M. (2007). Impact of employee participation on job satisfaction, employee commitment and employee productivity, International Review of Business Research Papers, 3, 54-68.

Bano, S., \& Wajidi, A. (2021). Role of Employee Behavior and Job Stress on Work-Life Balance: A Case of HEIs of Pakistan. Journal of Entrepreneurship, Management, and Innovation, 3(2), $177-201$.

Brown, B., McHardy, J., McNabb, R.,\& Taylor, K. (2011). Workplace performance, worker commitment and loyalty. IZA Discussion Paper No. 5447. 
Carmeli, A., \& Freund, A. (2004). Work commitment, job satisfaction, and job performance: an empirical investigation. International Journal of Organization Theory and Behavior, 6(4), $289-309$.

Chang, X., Zhou, Y., Wang, C., \& de Pablos Heredero, C. (2017). How do work-family balance practices affect work-family conflict? The differential roles of work stress. Frontiers of Business Research in China, 11(1), 8. Doi: https://doi.org/10.1186/s11782-017-0008-4

Dulebohn, J. H., Molloy, J. C., Pichler, S. M., \& Murray, B. (2009). Employee benefits: Literature review and emerging issues. Human Resource Management Review, 19(2),86- 103.

Employees' Old-Age Benefits Act. (1976). Government of Pakistan.

Fabiene, E.E. \& Kachchhap, S.L. (2016). Determinants of employee's commitment among healthcare professionals. International Journal of Academic Research in Accounting, Finance and Management Sciences, 6(2), 44-52.

Gul, Z. (2015). Impact of employee commitment on organizational development. FWU Journal of Social Sciences,9(2), $117-124$.

Gudep, V. K. (2019). An Empirical Study of The Relationships between The Flexible Work Systems (FWS), Organizational Commitment (OC), Work-Life Balance (WLB) and Job Satisfaction (JS) For the Teaching Staff in The United Arab Emirates (UAE). International Journal of Management, 10(5).

Haar, J. M., Sune, A., Russo, M., \& Ollier-Malaterre, A. (2019). A cross-national study on the antecedents of work-life balance from the fit and balance perspective. Social Indicators Research, 142(1), 261-282. Doi: https://doi.org/10.1007/s11205-018-1875-6

ILO (1952). The ILO Social Security (Minimum Standards) Convention, 1952 (No. 102)

Juliani, R., \& Purba, D. E. (2019). The mediating role of passion for work on the relationship between task significance and performance. Pertanika Journal of Social Sciences \& Humanities, 27(3), 1945-1958.

Judge, T. A., Thoresen, C. J., Bono, J. E., \& Patton, G. K. (2001). The job satisfaction-job performance relationship: A qualitative and quantitative review. Psychological Bulletin, 127(3), 376-407. https://doi. org/10.1037/0033-2909.127.3.376

Kiazad, K., Kraimer, M. L., \& Seibert, S. E. (2019). More than grateful: How employee embeddedness explains the link between psychological contract fulfillment and employee 
extra-role behavior. Human Relations, 72(8), 1315-1340. https://doi.org/10.1177/0018726718806352

Kovacevic, I., Cizmic, S.,\& Mihailovic, D. (2014). Operationalization of the work behaviour concept: work behaviour self-assessment scale. Revista Română de Statistică-Supliment, $7,32-47$.

Khan, K. I., Naqvi, S.M.W.A., Ghafoor, M.M., \& Nayab, G. (2020). Effect of reward system on innovative work behaviour through temporary organizational commitment and proficiency: moderating role of multiculturalism. International Journal of Management Research and Emerging Sciences, 10(2), 96 - 108.

Kumari, G., \& Pandey, K. M. (2011). Analysis of an individual's behaviour in work environment for a better output. International Journal of Innovation, Management and Technology, 2(2), $156-161$.

Kurose, C. (2013). Motivation, behavior, and performance in the workplace insights for student success in higher education. The George Washington University. Graduate School of Education and Human Development.

Lestari, N. D., \& Rizkiyah, N. (2021). The Workplace Stress and its Related Factors among Indonesian Academic Staff. Open Access Macedonian Journal of Medical Sciences, 9(T4), 70-76. Doi: https://doi.org/10.3889/oamjms.2021.5802

Loku, A., \& Gogiqi, F. (2016). Factors of individual behavior in an organization and its performance at work. IMPACT: International Journal of Research in Business Management, 4(5), $68-72$.

Lutz, V. R. (2011). Employee behavior in organizations: On the current state of research, Management Revue, 22(4), 344 - 366.

Machokoto, W. (2019). Employee Commitment Could Be Enhanced in the Healthcare Sector in the UK. International Journal of Psychology and Cognitive Science. 5(1), 24-29.

Matsuo, M. (2019). Effect of Learning Goal Orientation on Work Engagement through Job Crafting: A Moderated Mediation Approach. Personnel Review, 48(1), 220-233. ttps://doi.org/10.1108/PR-11-2017-0346

Meyer, J. P., Morin, A. J., \& Wasti, S. A. (2018). Employee commitment before and after an economic crisis: A stringent test of profile similarity. Human Relations, 71(9), 12041233. 
Mustafa, G., \& Ali, N. (2019). Rewards, autonomous motivation, and turnover intention: Results from a non-western cultural context. Cogent Business \& Management, 6(1), 1676090. (just-accepted). https:// doi.org/10.1080/23311975.2019.1676090

Nilsen, H. R., \& Ringholm, T. (2019). Lost in motivation? The case of a Norwegian community healthcare project on ethical reflection. Cogent Business \& Management, 6(1), 1632045. (just-accepted). https:// doi.org/10.1080/23311975.2019.1632045

Okemwa, Atambo, Muturi (2019). Influence of Employee Assistance Programs on Commitment of Nurses in Public Hospitals in Kenya, International Journal of Academic Research in Business and Social Sciences, 9,151-164.

Pakistan Economic Survey (2018-19). Finance Division. Government of Pakistan.

Pathak, P. K. (1988). 4 Simple random sampling. Handbook of Statistics, 6, 97 - 109

Peir'o, J. M., Bayona, J. A., Caballer, A., \& Di Fabio, A. (2020). Importance of work characteristics affects job performance: The mediating role of individual dispositions on the work design-performance relationships. Personality and Individual Differences, 157, 109808. https://doi.org/10.1016/j.paid.2019.109808

Pham, H. H. (2017). Determinants of job satisfaction and organizational commitment of employees within the telecommuting environment in Vietnam. International Journal of Scientific \& Engineering Research, 7(11), $1511-1520$.

Preacher, K. J., \& Leonardelli, G. J. (2001, March). Calculation for the Sobel test: An interactive calculation tool for mediation tests [Computer software]. Retrieved July 14, 2019, from http://www.unc.edu/ preacher/ sobel/sobel.htm

Rachael Pope, R., \& Burnes, B. (2007). Negative behaviour in the Workplace: A study of two Primary Care Trusts in the NHS. International Journal of Public Sector Management, 20(4), $285-303$.

Radosavljevic, Z., Cilerdzic, V., \& Dragic, M. (2017). Employee organizational commitment. Faculty of Business Economics and Entrepreneurship, 1(2), 18 -26.

Singh, J. P. (2016). Factors that influences human behavior at workplace: An overview. SOPAANII, $1(1), 12-17$.

Senol-Durak, E., Durak, M., \& Gencoz, T. (2021). Job satisfaction, and burnout as mediators of trait anger, work stress, positive and negative effect in a sample of Turkish correctional 
officers. The Journal of Forensic Psychiatry \& Psychology, 1-21. Doi: https://doi.org/10.1080/14789949.2021.1884738

Silva, C. T., Hakim, M. P., Zanetta, L. D. A., Pinheiro, G. S. D. D., Gemma, S. F. B., \& da Cunha, D. T. (2021). Burnout and food safety: Understanding the role of job satisfaction and menu complexity in foodservice. International Journal of Hospitality Management, 92, 102705. Doi: https://10.1016/j.ijhm.2020.102705

Sprigg, C.A., Martin, A., Niven, K., \& Armitage, C. J. (2010). Unacceptable behaviour, health, and wellbeing at work. IOSH Research Committee. The University of Sheffield.

Wasim ul Rehman, Razzaq, K., \& Zareen, M. (2020). Organizational climate and performance: mediating role of affective commitment, knowledge sharing practices and perceived cost of knowledge sharing. International Journal of Management Research and Emerging Sciences, 10(2), 72-84. 